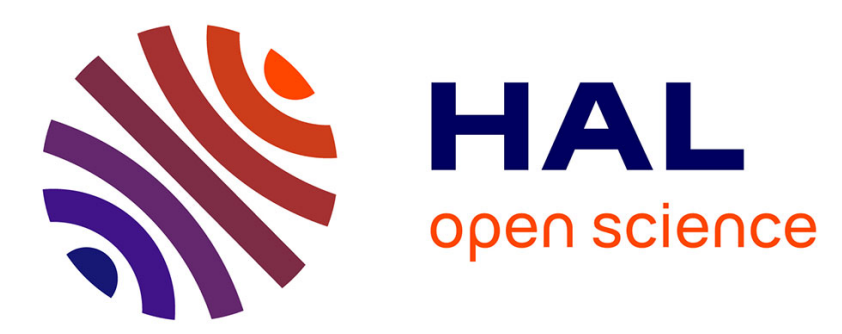

\title{
Shaving and breaking bacterial chains with a viscous flow
}

Faustine Gomand, William Mitchell, Jennifer Burgain, Jérémy Petit, Frédéric Borges, Saverio Spagnolie, Claire Gaiani

\section{- To cite this version:}

Faustine Gomand, William Mitchell, Jennifer Burgain, Jérémy Petit, Frédéric Borges, et al.. Shaving and breaking bacterial chains with a viscous flow. Soft Matter, 2020, 16 (40), pp.9273-9291. 10.1039/D0SM00292E . hal-03068227

\section{HAL Id: hal-03068227 \\ https://hal.univ-lorraine.fr/hal-03068227}

Submitted on 31 Aug 2021

HAL is a multi-disciplinary open access archive for the deposit and dissemination of scientific research documents, whether they are published or not. The documents may come from teaching and research institutions in France or abroad, or from public or private research centers.
L'archive ouverte pluridisciplinaire HAL, est destinée au dépôt et à la diffusion de documents scientifiques de niveau recherche, publiés ou non, émanant des établissements d'enseignement et de recherche français ou étrangers, des laboratoires publics ou privés. 


\section{Soft Matter}

\section{ARTICLE TYPE}

Cite this: DOI: $10.1039 / x x x x x x x x x x$

Accepted Date

DOI: $10.1039 / x x x x x x x x x x$

www.rsc.org/journalname

\section{The impact of shear stress on bacterial functionality and bacterial physical state : a theoretical and experi- mental study ${ }^{\dagger}$}

\author{
F. Gomand, ${ }^{a}$ S.E. Spagnolie, ${ }^{b}$ F. Borges,${ }^{a}$ J. Petit ${ }^{a}$, and C. Gaiani ${ }^{* a}$
}

\section{Introduction}

Lactic Acid Bacteria (LAB) have been long used as starter cultures in food manufacturing, especially of dairy products ${ }^{1-4}$. Recently, they have also been increasingly used when it comes to designing functional foods, due to their probiotic potential i.e. their ability to provide health benefits to their host ${ }^{4}$. Food manufacturing, storage, and digestion conditions, as well as food matrix structure and composition, have been shown to play an important role in enhancing or lowering LAB probiotic abilities ${ }^{5-7}$. In order to benefit human health, LAB cells not only need to remain viable but also functional, i.e. able to interact with their host through adhesive interactions and to multiply ${ }^{7}$. Whereas

\footnotetext{
${ }^{a}$ LIBio - Université de Lorraine, 2 avenue de la Forêt de Haye, 54500 Vandoeuvre-lèsNancy, France. Fax: 03-8359-5772; Tel: 03-7274-4111; E-mail: claire.gaiani@univlorraine.fr

${ }^{b}$ Department of Mathematics, University of Wisconsin-Madison, 480 Lincoln Dr., Madison, WI 53706, USA.

$\dagger$ Electronic Supplementary Information (ESI) available: Complete data set for microscopic observations on bacterial chain distribution. See DOI: 10.1039/cXsm00000x/
}

most studies have been able to assess reliably bacterial viability, bacterial functionality has often been neglected, because of its complexity which makes it difficult to ascertain. A common approach to evaluate LAB functionality consists of monitoring their adhesive behavior to models of intestinal cells, thus providing a proxy of bacterial ability to colonize the host; however, this approach alone remains unreliable, since dead bacteria have also been shown to adhere to Caco-2 cells but would later fail to multiply ${ }^{8,9}$. Up to now, clinical studies have been the most reliable way to assess bacterial functionality but remain very disparate thus hardly comparable to one another, therefore failing in providing guidelines to design efficient food matrices able to preserve bacterial functionality ${ }^{7}$. Factors likely to impact LAB functionality are numerous, ranging from their level of entrapment within the food matrix to the loss or inactivation of bacterial surface biomolecules modulating bacterial-host interactions and adhesion ${ }^{10}$. Exterior and environmental stresses may damage bacterial surface, thus altering bacterial cells adhesive abilities. Such stresses can occur in a wide variety of situations, including common food manufacturing steps, such as acidifica- 

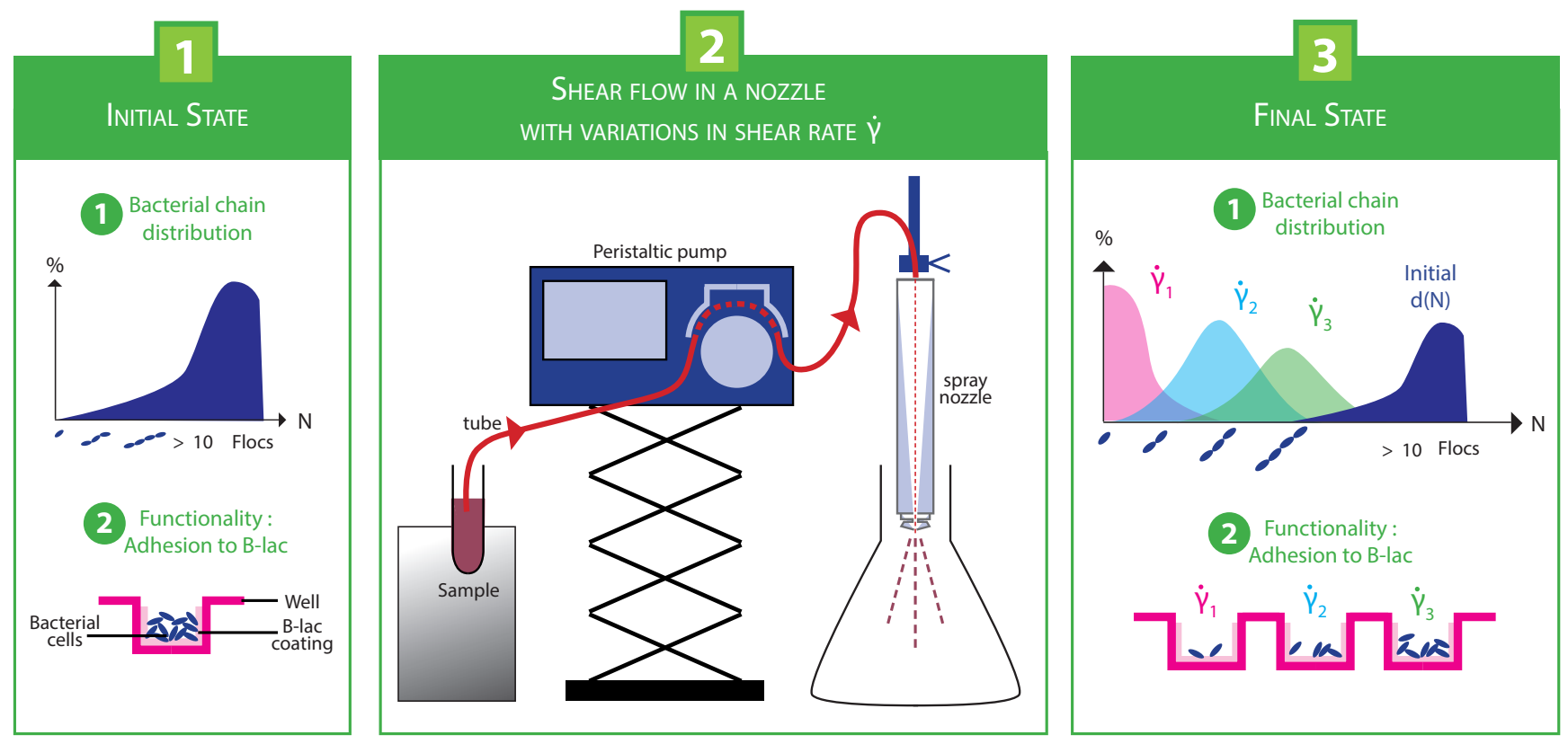

Fig. 1 Methodology and experimental configuration allowing evaluating the impact of shear stress on bacterial functionality (through bacterial adhesion) and bacterial physical state (through bacterial chain distribution).

tion $^{8}$, heat stress ${ }^{11}$, and spray-drying and extrusion, generative of shear stress ${ }^{11,12}$. Low-intensity heat stress may induce permanent structural changes related to significant cell collapse and membrane integrity loss, and also leads to bacterial chains fragmentation ${ }^{11}$, which would prevent bacterial cells from colonizing the host. Similarly, powder formulation and LAB encapsulation performed through spray-drying were also shown to impact bacterial physical state causing bacterial chains to break, thus resulting in an apparent increase in bacterial cells concentration in sprayed solution ${ }^{12}$. Although bacterial viability was found to be little impacted by spray-drying in this latter study, no insight was provided on the impact of this process on bacterial functionality; therefore bacteria may have survived but their surface could have been damaged, thus rendering them unable to adhere to the host. In the case of Gram-positive bacteria, bacterial adhesion is known to be mediated by sortase-dependent proteins ${ }^{13,14}$, which are covalently anchored to the cell wall and possess an LPxTG like motif at their C-terminal end ${ }^{15}$. The model strain Lactobacillus rhamnosus GG (LGG) features well-known adhesive capabilities ${ }^{16-18}$ mediated by pili, which are filamentous, proteinaceous surface appendages found in both Gram-negative and Gram-positive bacteria ${ }^{19-21}$. The role of pili in maintaining attachment to surfaces or to optimize surface colonization in stressful conditions has previously been investigated ${ }^{22,23}$. Cell adhesion forces range from a few to hundreds of picoNewtons, which is sufficient to maintain attachment in a variety of flow environments. In some rare cases, bacterial strains are able to withstand shear stresses as high as $1 \mathrm{MPa}^{22}$. Pathogenic strains featuring type I and type IV-pili were even found to feature shear stress-enhanced adhesive properties $^{24-26}$, which can for low stresses participate in biofilm formation ${ }^{22}$. Although most studies have focused on describing pili belonging to Gram-negative bacteria and, more generally, bacteria responsible of infections, to our best knowledge no study has yet described the impact of shear stress on pili featured by probiotic bacteria, despite the fact that these pili mediate adhesion to the host and are therefore crucial to ensure probiotic action. In this article, we investigate the impact of shear stress generated by spray-drying on bacterial functionality and in particular on LGG pili, assessed using the method developed by Gomand et al. $(2018)^{27}$. One great advantage of this method consists in allowing assessing at the same time both bacterial functionality as well as bacterial viability by correlating bacterial adhesion with bacterial growth, thus providing a more global insight on the impact of the process on the maintenance of probiotic abilities in response to stress. Bacterial chain breakage phenomenon, as previously observed as a response to shear stress, is also monitored in order to determine whether or not a relationship between bacterial functionality and bacterial physical state can be drawn.

\section{Experimental}

\subsection{Experimental shearing}

Bacterial adhesion to $\beta$-lactoglobulin and bacterial chain distribution were evaluated experimentally on model strains before and after shearing in order to estimate the impact of shear stress on bacterial functionality (bacterial adhesion standing for a proxy of bacterial surface integrity) and bacterial physical state. Bacterial adhesion to Bovine Serum Albumin (BSA), to which LGG has been found to feature low adhesive affinities $18,27,28$ was also recorded as a negative control. Experimental configuration and steps are represented in Figure 1. The experimental steps followed to achieve this goal are detailed in following sections. 


\subsubsection{Bacterial strains and cultures.}

Four strains were used in this study: the model strain Lactobacillus rhamnosus GG ATCC53103 (LGG wild type, "WT") and the three derivative mutant strains LGG spaCBA CMPG 5357, impaired in pili synthesis ${ }^{29}$, LGG welE CMPG5351, impaired in exopolysaccharides (EPS) production ${ }^{30}$, and LGG welE-spaCBA CMPG5355, double mutant ${ }^{17}$. These strains feature well-known adhesion properties that have been previously described ${ }^{17,18,29,31}$.

All strains were pre-cultivated at $37{ }^{\circ} \mathrm{C}$ overnight in $10 \mathrm{~mL}$ of liquid MRS medium (de Man, Rogosa and Sharpe) inoculated each with $100 \mu \mathrm{L}$ of frozen cultures stored at $-80{ }^{\circ} \mathrm{C}$. The next day, $100 \mu \mathrm{L}$ of the pre-cultures were used to inoculate $10 \mathrm{~mL}$ of liquid MRS medium and left for incubation at $37^{\circ} \mathrm{C}$ until the suspensions reached an optical density of 0.8 at $595 \mathrm{~nm}\left(\mathrm{OD}_{595 \mathrm{~nm}}\right.$ $=0.8$ ). Suspensions were then centrifuged at 3,618 g (i.e. 3,000 rcf) for $10 \mathrm{~min}$. The resulting cell pellets were resuspended in Phosphate Buffered Saline (PBS) adjusted at pH 6.8 and bacterial suspensions were subsequently used for shearing experiments. Triplicates on independent cultures were performed as well as six repetitions by strain for a given culture.

\subsubsection{Preparation of the $\beta$-lactoglobulin solution and mi- croplate coating.}

$\beta$-lactoglobulin (Sigma-Aldrich Co. LLC, St Louis, MO, USA) and BSA were prepared in solution ( $1 \% \mathrm{w} / \mathrm{w})$ as described by Gomand et al. ${ }^{27}$. Briefly, solutions were left homogenizing for a minimum of $2 \mathrm{~h}$, and then $200 \mu \mathrm{L}$ were introduced by well on highbinding 96-well microplates, each microplate containing half- $\beta$ lactoglobulin, half BSA. Microplates were stored overnight at $9{ }^{\circ} \mathrm{C}$ to allow biomolecules immobilization. Wells were washed twice the next day with $300 \mu \mathrm{L}$ of Phosphate Buffered Saline (PBS, P4417, Sigma-Aldrich Co. LLC, St Louis, MO, USA) supplemented with the blocking reagent Tween 20 (PBST, $5 \%$ Tween $20 \mathrm{v} / \mathrm{v}, \mathrm{pH}$ adjusted at 6.8), and subsequently used for adhesion assays.

\subsubsection{Shearing process and characteristic atomization shear rates.}

Bacterial suspensions were sheared at laboratory scale using a two-fluid spray-drying nozzle with a Fluid Cap 60100 / Air Cap 120 configuration (Spraying Systems Co., Wheaton, IL, USA; inner and outer diameters for the liquid channel $D_{i_{L}}=1.524 \mathrm{~mm}$, $D_{o_{L}}=2.540 \mathrm{~mm}$; air hole diameter $\mathrm{D}_{A}=3.048 \mathrm{~mm}$ ). The bacterial suspension was pumped into the nozzle using a peristaltic pump (reference number 324064, VWR International Europe bvba, Leuven, Belgium) connecting the sample with the nozzle with a $48 \mathrm{~mm}$-diameter tube such as presented in Fig.1. Pumping was performed at constant liquid flow rate $\dot{q}_{B}=20.3 \pm$ $0.32 \mathrm{~mL} . \mathrm{s}^{-1}$. Shear rate were manipulated by altering the flow rate of atomizing air through the nozzle. Air pressures used were respectively of $0.2,0.4,0.6,1$, and 4 bars.

To determine the shear rates values corresponding to the range of air pressures we used, we relied on a previous study performed by Ghandi et al. (2012) ${ }^{32}$ as well as on a review on two-fluid atomization written by Hede et al. (2008) ${ }^{33}$. Ghandi et al. give directions to determine characteristic shear rates for an external mixing type two-fluid nozzle such as represented in Figure 2 knowing the velocities of air and bacterial suspension $v_{A}, v_{B}$, the mass and volumetric flow rates of air and bacterial suspension $\dot{m}_{A}, \dot{q}_{A}, \dot{m}_{B}, \dot{q}_{B}$, and nozzle characteristics (diameters $D_{i_{L}}, D_{o_{L}}$, $\left.D_{A}\right)$. Hede et al. give a more comprehensive overview of the effect of formulation, nozzle geometry, and feed and gas flow rates for two-fluid nozzles introducing basic nozzle theory and thermodynamics, and can be referred to for more detailed information on these matters ${ }^{33}$.
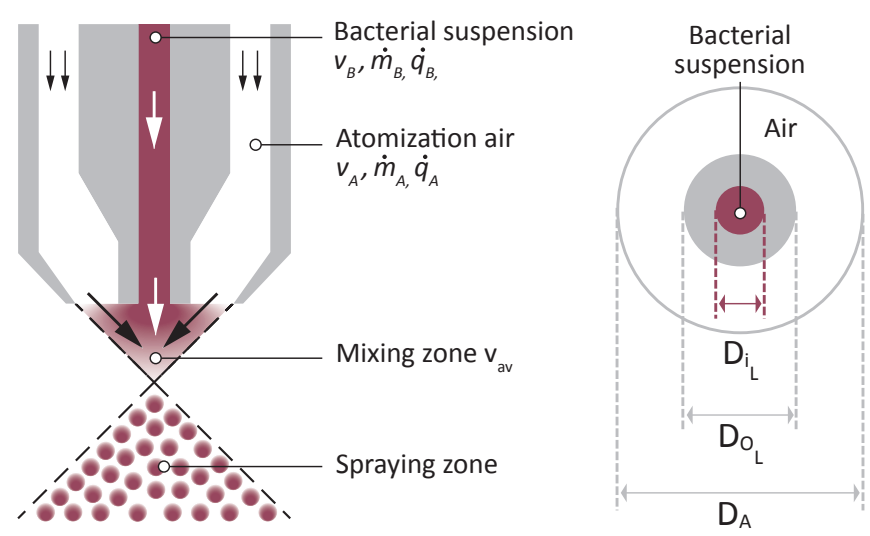

Fig. 2 Vertical (left) and horizontal (right) cross-sections of the external two-fluid nozzle used subsequently for shearing experiments, adapted from Ghandi et al. (2012) ${ }^{32}$.

Characteristic shear rates have been calculated based on the two following equations described by Ghandi et al. (2012) ${ }^{32}$ :

$$
\begin{gathered}
\dot{\gamma}=\frac{2\left(v_{a v}-v_{B}\right)}{D_{i_{L}}} \\
v_{a v}=\frac{v_{A} \dot{m}_{A}+v_{B} \dot{m}_{B}}{\dot{m}_{A}+\dot{m}_{B}}
\end{gathered}
$$

Where $v_{a v}$ is the average velocity in the mixing zone, assuming transfer of momentum between the bacterial suspension and air which both leave the atomization zone at constant velocity. In equations (1), (2), characteristic shear rate $\dot{\gamma}$ is expressed in $\mathrm{s}^{-1}$, velocities in $\mathrm{m} . \mathrm{s}^{-1}$, mass flow rates in $\mathrm{kg} . \mathrm{s}^{-1}$, and inner diameter of the liquid $D_{i_{L}}$ in $\mathrm{m}$. Air and liquid velocities have been calculated using the following relationships:

$$
\begin{gathered}
v_{A}=\frac{\dot{q}_{A}}{\frac{\pi D_{A}^{2}}{4}-\frac{\pi D_{O_{L}}^{2}}{4}} \\
v_{B}=\frac{4 \dot{q}_{B}}{\pi D_{i_{L}}^{2}}
\end{gathered}
$$

The liquid and air flow rates $\dot{q}_{B}, \dot{q}_{A}$ were determined experimentally; $\dot{q}_{B}$ was found to be independent from the value of air pressure used, and $\dot{q}_{A}$ was measured using a gas meter (Itron Gallus G4) for air pressures of $0.2,0.4,0.6$, and 1 bar. This experimental set of flow rates was combined with the nominal set of flow rates specific to our nozzle (Spraying Systems Co., Wheaton, IL, USA) and a polynomial model was fitted allowing predicting the 
air flow rates as a function of air pressure:

$$
\dot{q}_{A}=-1.67 P^{2}+26.78 P+30.58, \quad R^{2}=0.999
$$

The mass flow rates have been calculated using the relation $\dot{m}=\rho \dot{q}$ where $\rho$ is the fluid density (in $\mathrm{kg} . \mathrm{m}^{-3}$ ) and $\dot{q}$ the volumetric flow rate $\left(\mathrm{m}^{3} \cdot s^{-1}\right)$. The bacterial suspension density $\rho_{B}$ has been determined experimentally. The relevant parameters used to determine characteristic shear rates have been gathered in Table 1.

Table 1 Parameters used to determine characteristic shear rates used in this study; the different values of $\dot{q}_{A}$ presented correspond to different air pressures $(0.2,0.4,0.6,1$, and 4 bars $)$

\begin{tabular}{lll}
\hline Parameter & Bacterial suspension & Air \\
\hline$D_{i}(\mathrm{~mm})$ & 1.524 & 3.048 \\
$D_{O}(\mathrm{~mm})$ & 2.540 & NA \\
$\rho\left(\mathrm{kg} \cdot \mathrm{m}^{-3}\right)$ & 1025.8 & 1.204 \\
$\dot{q}\left(\mathrm{~L} \cdot \mathrm{min}^{-1}\right)$ & $20.3 \times 10^{-3} \pm 0.32$ & $34.8 \pm 0.4$ \\
& & $41.8 \pm 0.4$ \\
& & $47.2 \pm 0.7$ \\
& & $54.8 \pm 1.2$ \\
& & 111 (fitted nominal value) \\
\hline
\end{tabular}

For a given air pressure, flow was adjusted before collecting the output. Five milliliters of output bacterial suspension were collected for each value of air pressure at a distance of about $50 \mathrm{~cm}$ of the nozzle exit, at ambient temperature. This allowed avoiding altering droplet formation in the spray while optimizing atomized concentrate recovery ${ }^{32}$. Five milliliters of output were also collected when no air pressure went through the nozzle (the air channel was then disconnected) as a control, to determine whether going through the nozzle itself could impact bacterial functionality even in the absence of air pressure. In this case, control shear rate shall be determined using the following formula:

$$
\dot{\gamma}_{c t r l}=\frac{2 v_{B}}{D_{i_{L}}}
$$

Based on these calculations, the characteristic shear rates we used during our experiments have been gathered in Table 2. Based on

Table 2 Characteristic shear rates and corresponding air pressures used in the experimental part of this study

\begin{tabular}{ll}
\hline Air pressure (bars) & Characteristic shear rate $\left(10^{5} \mathrm{~s}^{-1}\right)$ \\
\hline 0 & 0.00244 \\
0.2 & 3.0 \\
0.4 & 3.7 \\
0.6 & 4.2 \\
1.0 & 4.9 \\
4.0 & 11 \\
\hline
\end{tabular}

this table, a direct relation of proportionality can be established between the value of air pressure used and the corresponding shear rate such as:

$$
\dot{\gamma} \approx\left(2.0 \times 10^{5}\right) P+\left(2.8 \times 10^{5}\right), \quad R^{2}=0.996
$$

with $\dot{\gamma}$ in $\mathrm{s}^{-1}$ and $P$ in bars.

We also evaluated the effect of a repeated stress by comparing results obtained for the highest shear rate when applied once versus three times in a row for the same bacterial suspension.

\subsubsection{Functionality assessment.}

Bacterial functionality was assessed through the proxy of bacterial adhesion to $\beta$-lactoglobulin using the method described by Gomand et al. (2018) ${ }^{27}$. Briefly, bacterial suspensions after shearing, as well as control bacterial suspensions, were diluted until reaching an $\mathrm{OD}_{5} 95 \mathrm{~nm}$ of 0.5 . One hundred and twenty milliliters were then introduced into each well of the high-binding 96-well microplates where the milk biomolecules had been immobilized and left $1 \mathrm{~h}$ for incubation at $37^{\circ} \mathrm{C}$. Each well was then washed 5 times using $300 \mu \mathrm{L}$ of PBST (pH 6.8) for 96-well microplates to eliminate non-adherent strains. Two hundred microliters of MRS were finally introduced into each well and bacterial growth was monitored through $\mathrm{OD}_{595 \mathrm{~nm}}$ measurements over $20 \mathrm{~h}$. The quicker the apparent growth starts, the higher the bacterial affinity towards $\beta$-lactoglobulin, i.e. the less shear-impacted the bacterial suspension. Strain growth comparison was performed using times at which the apparent bacterial growth starts. These time values $\left(\mathrm{t}_{\text {start }}\right)$ match an $\mathrm{OD}_{595 \mathrm{~nm}}$ threshold which was defined according to the baseline corresponding to the absence of growth detection $^{27}$. In order to be proportionally and visually representative of adhesion ability the value of $1000 / \mathrm{t}_{\text {start }}$ was calculated.

\subsubsection{Bacterial chain distribution assessment.}

Bacterial chain distribution assessment was evaluated visually through microscopic observations. For each assay, $5 \mu \mathrm{L}$ were collected by shearing condition from $1 \mathrm{~mL}$ of half-diluted bacterial suspensions, dried, stained with crystal violet and washed with distilled water. Microscopic observations were performed using an Olympus microscope alongside with Toupcam software. Thirty pictures were taken and analyzed by condition.

\subsubsection{Data treatment and statistics.}

Bacterial functionality results were standardized by experiment using the measured adhesion of control LGG WT to $\beta$ lactoglobulin.

Distinct categories created to assess bacterial chain distribution include from single cells to 10-cell chains, chains featuring more than 10 cells (which will be called 'long chains' throughout the text), and flocs. Bacterial cells forming flocs were not counted twice (i.e., they were not included in another categories). Flocs have been defined to stand for bacterial cells that either (i) stick together by their sides (and not their ends), meaning that they were not initially part of the same chain, when 3 or more cells are stuck in parallel (ii) bend excessively such as forming apparent "nodes", suggesting that the chain will not recover its initial form, when two or more chains close to one another bend excessively (iii) combined both bending and sticking characteristics. The floc type (ii) has been previously shown to be caused by mechanical strain sensing amongst other factors, which was identified as an important component of bacterial cell shape regulation for Escherischia coli ${ }^{34}$. Bacterial floc types are represented in Figure 3. Flocs can be of various sizes, as long as all cells within the flocs remain connected to one another.

Cross-analysis were performed via a Tukey test (parametric for multiple comparisons) for normal data and a Steel-Dwass test (non-parametric, multiple comparison test) for data that did not 


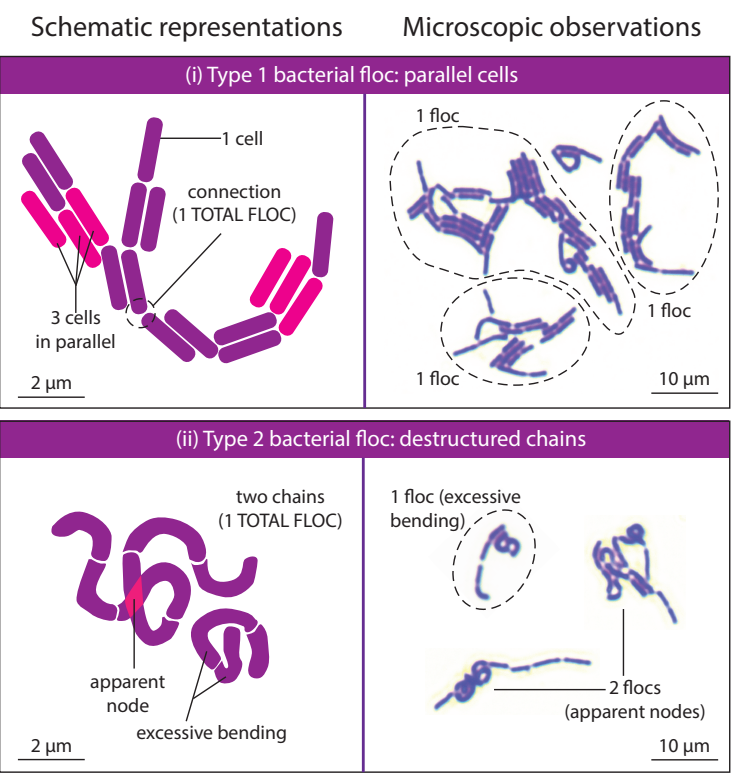

Fig. 3 Representation of bacterial flocs types: parallel bacterial cells (i) and destructured chains (ii); representative microscopic pictures of Lactobacillus rhamnosus GG WT for each floc type are presented to illustrate the proposed schematic representations.

fit normal distribution using Kyplot software (Kyens Lab Inc.) to highlight the main observed differences by strain between the different shear stress conditions.

\subsection{Model and numerics}

\section{Experimental results and discussion}

\subsection{Bacterial chain distribution}

Bacterial chain distribution have been monitored before and after shearing for the characteristic shear rates of 0.00244, 3.0, 3.7, 4.2, 4.9, and $1110^{5} \mathrm{~s}^{-1}$ for LGG WT, LGG spaCBA, and LGG welE and are presented in Figure 4 for shear rates at the extremes of the spectrum: $0.00244,3.0,4.9$, and $1110^{5} \mathrm{~s}^{-1}$. Comprehensive data sets for all shear rates tested are available in Electronic Supplementary Information (ESI) $\dagger$.

All strains feature a majority of long chains (length superior to 10 cells) in their initial state before shearing, accounting for about $25 \%$ of the total number of chains and flocs present in solution, whichever the strain is. Flocs also represent an important proportion of the initial volume, proportion however more disparate between strains, varying from $16 \%$ for LGG welE to more than 30 $\%$ for LGG spaCBA. Little or none single cells were found initially, and distribution of other chain lengths appears to be randomly distributed, with proportions varying between 1 and $10 \%$.

When sheared at very low shear rate $\left(244 \mathrm{~s}^{-1}\right)$ with no air pressure, the chain distribution of LGG WT remains mostly similar to the control. For the two other strains, however, a significant decrease in long chains occur, of about $10 \%$ for both LGG spaCBA and LGG welE. This loss is compensated by a proportional increase of 2-cell chains for LGG welE, whereas it is more homogeneously divided between the different chain lengths categories for LGG
spaCBA.

When performing atomization even for very low air pressures, the proportion of 2 cell-chain drastically increases by a factor of 6 , representing at least $35 \%$ of the total number of chains and flocs in solution, and almost all chains featuring more than 4 cells get broken whichever strain is considered. Proportion of chains featuring from 7 to more than 10 cells remains inferior to $1 \%$; 6-cell and 5 -cell chains represent each around $2 \%$ of the total number of chains and flocs (up to $4 \%$ for LGG welE). The proportion of 4-cell chains also increases of $10 \%$ for low air pressures for the strains LGG WT and spaCBA.

The strain LGG spaCBA is the one the less impacted at low air pressures in terms of chain breakage, as 2-cell chains represent only $35 \%$ of the total, versus $50 \%$ or more for the two other strains. LGG spaCBA is also the strain the most likely to flocculate, flocs representing the major category of bacterial organization even in the initial solution, before long chains. For this strain, the increased proportion of 2-cell chains due to shearing may result from flocs breakage instead of chain breakage (proportions loss and increase being relatively similar). Given the fact that 50 $\%$ of 2-cell chains is reached for a shear rate of $4.9 \times 10^{5} \mathrm{~s}^{-1}$ for LGG spaCBA versus for a shear rate of $3.0 \times 10^{5} \mathrm{~s}^{-1}$ for LGG WT and welE, it can be argued that flocs are maintained by forces more difficult to break than those maintaining bacterial chain integrity, thus, flocculating tend to preserve bacterial chains from breaking.

Most of the shearing impact on bacterial chain distribution can be observed for an air pressure of 0.2 bars $\left(\dot{\gamma}=3.0 \times 10^{5} \mathrm{~s}^{-1}\right)$. Higher shear rates generate very little additional change in bacterial distribution. Globally, all proportions of chains featuring more than 2 cells decrease (up to $10 \%$-decrease). However, some additional changes appear to be more strain-dependent. Proportion of 2-cell chains does not change much for LGG WT and LGG welE, but keep on increasing for LGG spaCBA until reaching a threshold similar to the two other strains (between 50 and 60 $\%$, while the number of flocs of LGG spaCBA keeps on decreasing proportionally. Very high pressures are required to obtain single cells, which proportion gradually increases for LGG WT as shear rate increases, whereas it suddenly increases of respectively 10 and $20 \%$ for the two mutant strains spaCBA and welE.

Overall, this suggests that chain breakage is more likely to occur for strains organized in long chains than for strains which tend to flocculate, and that it occurs even when low air pressures are applied ( $P=0.2$ bars, $\dot{\gamma}=3.0 \times 10^{5} s^{-1}$.). In fact, most breakage events occur at very low air pressures and lead to a drastic increase in 2-cell chains, which seem to be the major and most stable form for bacterial chains in flow. Indeed, this form is able to resist even shear rates as high as $11 \times 10^{5} \mathrm{~s}^{-1}$ and still not break. Higher shear rates than $3.0 \times 10^{5} \mathrm{~s}^{-1}$, although not inducing as drastic a change to bacterial chain distributions compared to low shear rates, generate additional strain-dependent breakage and lead to an increase proportion of single cells. A hypothesis for why 2-cell chains appear to be a more favorable configuration in shear flow than longer chains or single cells could be that forces exerted on the bodies of a 2-cell chains are minimized compared to other forms, due to its symmetry but also to its very short 

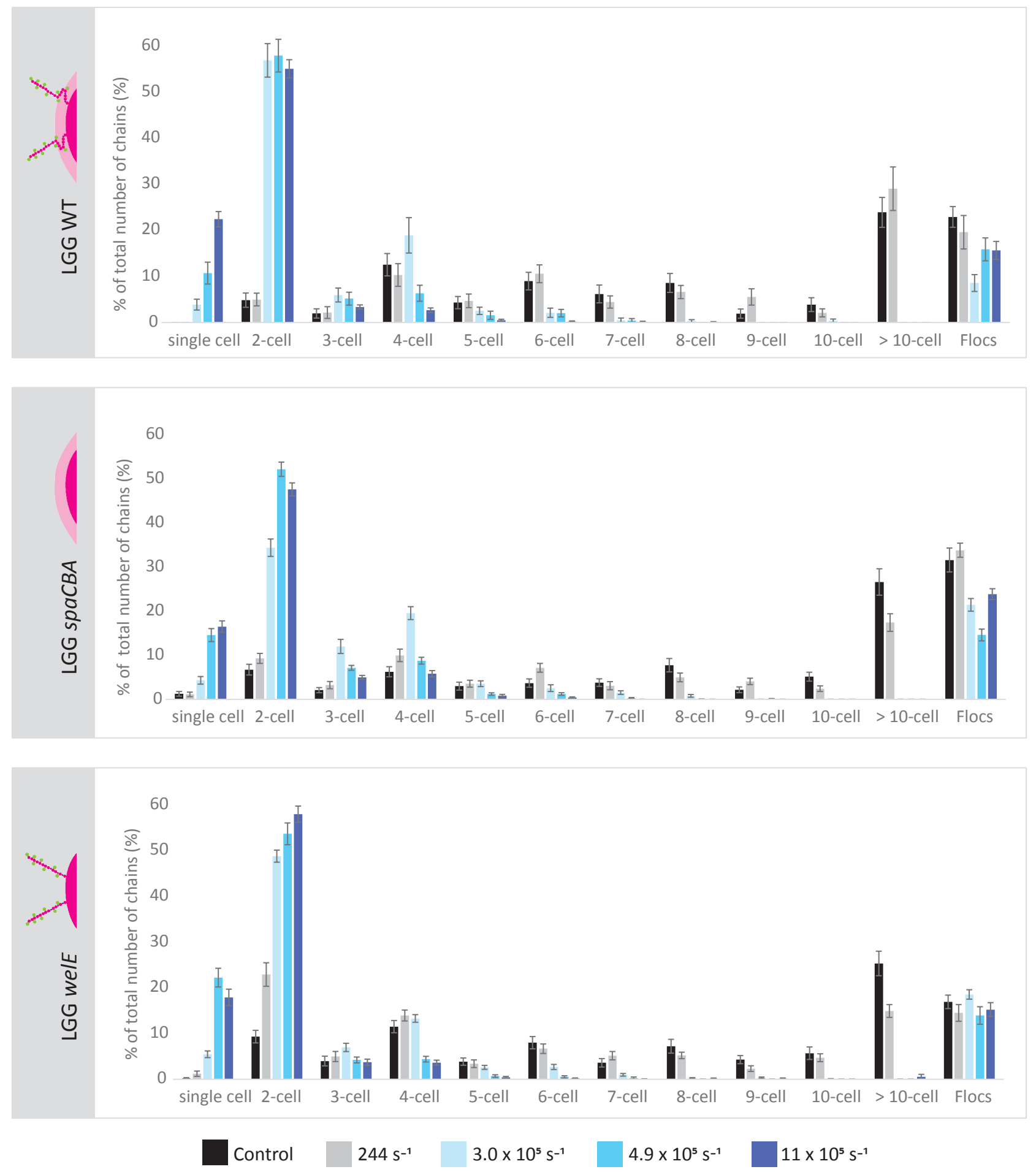

Fig. 4 Chain distribution for the strains Lactobacillus rhamnosus GG "wild type" (WT), spaCBA, and welE before and after shearing for shear rates of $0.00244,3.0,4.9$, and $1110^{5} \mathrm{~s}^{-1}$. Chain categories include single cells, 2-cell to 10-cell chains, chains longer than 10-cells, and flocs. Standard errors are presented.

length; exposure to traction forces would therefore be reduced. This hypothesis will be furthered explored in the modeling part.

Four-cell chains is the second major and most stable form; its breakage occurs in parallel of an increase in proportions of single cells and 2-cell chains, suggesting that it would break in 3 pieces,
2 single chains and 12 -cell chains. The way bacterial chains break will also be furthered explored in the modeling part.

The effect of repeated shear stress versus punctual shear stress on bacterial chain distribution have been gathered in Table 3 for LGG WT, spaCBA, and LGG welE using a characteristic shear rate 
Table 3 Impact of repeated shear stress ('Repeated') versus punctual shear stress ('Punctual') at high shear rates $\left(11 \times 10^{5} \mathrm{~s}^{-1}\right)$ on bacterial chain distribution (in \% of total number of chains and flocs) for Lactobacillus rhamnosus GG, spaCBA, and welE; standard errors are presented for 30 measurements; different letters within the same row for a given strain attest of statistically significant differences by strain

\begin{tabular}{|c|c|c|c|c|c|c|c|c|c|}
\hline & & LGG WT & & & LGG spaCBA & & & LGG welE & \\
\hline & Control & Punctual & Repeated & Control & Punctual & Repeated & Control & Punctual & Repeated \\
\hline$\overline{\text { Single cells }}$ & $0.0 \pm 0.0^{a}$ & $22 \pm 1.7^{b}$ & $38 \pm 2.0^{c}$ & $1.2 \pm 0.5^{a}$ & $16 \pm 1.3^{b}$ & $36 \pm 1.1^{c}$ & $0.18 \pm 0.18^{a}$ & $18 \pm 1.8^{b}$ & $52 \pm 2.4^{c}$ \\
\hline 2-cell chains & $4.8 \pm 1.5^{a}$ & $55 \pm 2.0^{b}$ & $47 \pm 2.4^{b}$ & $6.7 \pm 1.2^{a}$ & $48 \pm 1.5^{b}$ & $43 \pm 1.0^{b}$ & $9.3 \pm 1.3^{a}$ & $58 \pm 1.8^{b}$ & $33 \pm 2.0^{c}$ \\
\hline 3-cell chains & $2.0 \pm 1.0^{a}$ & $3.4 \pm 0.45^{b}$ & $1.4 \pm 0.43^{a}$ & $2.1 \pm 0.58^{a}$ & $5.0 \pm 0.43^{b}$ & $3.4 \pm 0.31^{c}$ & $4.0 \pm 1.1^{a}$ & $3.7 \pm 0.68^{a}$ & $2.9 \pm 0.89^{a}$ \\
\hline 4-cell chains & $12 \pm 2.4^{a}$ & $2.6 \pm 0.51^{b}$ & $1.6 \pm 0.35^{b}$ & $6.2 \pm 1.1^{a}$ & $5.8 \pm 0.71^{a}$ & $1.7 \pm 0.29^{b}$ & $11 \pm 1.3^{a}$ & $3.6 \pm 0.55^{b}$ & $0.33 \pm 0.22^{c}$ \\
\hline Flocs & $23 \pm 2.2^{a}$ & $16 \pm 2.0^{b}$ & $11 \pm 2.2^{b}$ & $32 \pm 2.7^{a}$ & $24 \pm 1.2^{b}$ & $16 \pm 0.65^{c}$ & $17 \pm 1.5^{a}$ & $15 \pm 1.5^{a b}$ & $11 \pm 1.1^{b}$ \\
\hline
\end{tabular}

of $11 \times 10^{5} \mathrm{~s}^{-1}$. Initial chain distributions are used as controls. Only impacted bacterial chain categories are presented in Table 3. Comprehensive data sets including results for other categories are available in ESI $\dagger$.

Repeated shear stress reduces the proportion of all kind of chains and proportionally increases the proportion of single cells whatever the strain considered. However, the intensity of the impact of repeated stress appears to be both strain- and chain length-dependent. When comparing between strains, the chain distribution of the mutant strain LGG welE is indeed more impacted than the chain distribution of the two other strains. The proportion of single cells of LGG welE increases by a factor of 2.5 for repeated stress vs. punctual stress while the proportion of 2 -cell chains gets divided by a factor of 2 , whereas only a small decrease (not statistically significant) is observed for this same category for both LGG WT and spaCBA. Similarly, 4-cell chains proportion gets divided by a factor of 10 for LGG welE, whereas it only gets divided by two for LGG WT and by three for LGG spaCBA. LGG welE appears therefore to be more sensitive to repeated shear stress than the two other strains.

When comparing for chain lengths for LGG WT, 3-cell and 4cell chains appear to be more sensitive to repeated shear stress than 2-cell chains and flocs. For both these latter categories, the impact of repeated stress compared to punctual stress was not demonstrated statistically, although trends can be observed in average. A similar phenomenon can be observed for LGG spaCBA, which proportion of 2-cell chains does not seem to be impacted by repeated stress compared to shear stress. However, proportions of 3-cell and 4-cell chains are significantly reduced by repeated stress vs. punctual stress, reduction factors being respectively of 1.6 and 3. This suggests that the increase in single cells when higher shear rates are applied actually results more from the ruptures of 4-cell and 3-cell chains than of 2-cell chains for LGG WT. Proportion of flocs decrease for both strains due to repeated vs. punctual stress, although this decrease is only significant for the mutant strain LGG spaCBA. Flocs breakage may also provide for the increase proportion of single cells. It appears that flocs of LGG spaCBA are more sensitive to repeated stress than flocs of LGG WT, which may be due to the absence of pili on LGG spaCBA which would help maintaining floc cells together. Pönisch et al. (2016) indeed previously show that certain types of pili mediate the dynamics of single cells and cellular aggregates ${ }^{35}$.

When comparing the sensitivity of chain lengths for LGG welE, a sensitivity gradient appears: 4-cell chains are the most impacted, then 2-cell chains, then flocs. The impact of repeated stress com- pared to punctual stress was not supported statistically for 3-cell chains, although a trend can be observed.

This suggests that the impact of repeated stress on bacterial cells depends both on the strain considered and preferred bacterial organization (chain lengths and flocs). Whereas punctual stress does not seem to be able to break 2-cell chains even when high shear rates are applied (Figure 4), repeated stress is able to do so, and the intensity of this breakage was found to be strainsensitive. Flocs seem to be the most resistant configuration to stress, whether punctual or repeated, as the floc proportion remain little impacted in any case. LGG welE has found to be the strain the most sensitive to repeated shear stress in terms of bacterial physical state amongst the three strains tested. Two hypothesis can be made to explain this fact. The first one could be that because this strain is impaired in EPS, connections between cells within a chain are less protected from outer stresses. However, this hypothesis does not explain the differential impact of stress as a function of chain length, especially for repeated stress. The second hypothesis relates to the fact this strain is most adhesive of the three due to increased pili exposure ${ }^{18,28}$. This could have caused it to adhere to the walls of the nozzle while getting through, thus resulting in increasing traction forces exerted on bacterial chains attached to the walls, causing them to break more. Proximity to the walls could be fostered for some chain types, therefore resulting in differential stress impact for different chain lengths. Differential distribution of cells in stream channels is indeed a long-observed phenomenon in cardiology research $^{36,37}$, where it has been identified as one of the factor leading to differential adhesion to the channel walls, alongside with shear-enhanced diffusivity due to high granular pressure ${ }^{37,38}$.

\subsection{Bacterial functionality}

The impact of shear stress on bacterial adhesive functionality was evaluated for shear rates ranging from $244 \mathrm{~s}^{-1}$ to $11 \times 10^{5} \mathrm{~s}^{-1}$ for all LGG WT and the three mutant strains LGG spaCBA, LGG welE, and the double mutant LGG welE-spaCBA (LGG D2). Results are presented in Table 4 and have been expressed both in $1000 / \mathrm{t}_{\text {start }}$ (normalized on the adhesion of the control LGG WT to $\beta$-lactoglobulin) to allow inter-strain comparison, and in percentages of functionality losses (assuming the bacterial functionality of the control for each strain is equal to $100 \%$ ) to allow intra-strain comparison.

Although overall bacterial adhesive functionality appears to be little affected by shear stress for most strains, whichever shear rate is considered, this shear stress impact appears to be highly 
Table 4 Impact of shear stress on bacterial adhesive functionality for Lactobacillus rhamnosus GG 'wild type' (LGG WT) and the three mutant strains LGG spaCBA, welE, and double mutant D2 (welE-spaCBA); standard deviations are presented; different letters within the same $1000 / t_{\text {start }}$ column attest of statistically significant differences

\begin{tabular}{|c|c|c|c|c|c|c|c|c|}
\hline \multirow{2}{*}{$\dot{\gamma}\left(10^{5} \mathrm{~s}^{-1}\right)$} & \multicolumn{2}{|l|}{$\overline{\mathrm{LGG} W T}$} & \multicolumn{2}{|c|}{$\overline{\text { LGG spaCBA }}$} & \multicolumn{2}{|c|}{$\overline{\text { LGG welE }}$} & \multicolumn{2}{|c|}{$\overline{\mathrm{LGG}} \mathrm{D} 2$} \\
\hline & $1000 / \mathrm{t}_{\text {start }}\left(\mathrm{s}^{-1}\right)$ & Loss (\%) & $1000 / \mathrm{t}_{\text {start }}\left(\mathrm{s}^{-1}\right)$ & Loss (\%) & $1000 / \mathrm{t}_{\text {start }}\left(\mathrm{s}^{-1}\right)$ & Loss (\%) & $1000 / \mathrm{t}_{\text {start }}\left(\mathrm{s}^{-1}\right)$ & Loss (\%) \\
\hline Control & $1.0 \pm 0.09^{a}$ & 0 & $0.41 \pm 0.05^{a}$ & 0 & $1.8 \pm 0.09^{a}$ & 0 & $0.77 \pm 0.02^{a}$ & 0 \\
\hline 0.00244 & $1.0 \pm 0.14^{a}$ & -1 & $0.41 \pm 0.04^{a}$ & 0.5 & $1.5 \pm 0.06^{b}$ & 17 & $0.70 \pm 0.01^{b}$ & 9 \\
\hline 3.0 & $1.0 \pm 0.16^{a}$ & -5 & $0.50 \pm 0.07^{b}$ & -22 & $1.6 \pm 0.04^{b}$ & 11 & $0.71 \pm 0.01^{a c}$ & 8 \\
\hline 3.7 & $1.0 \pm 0.13^{a}$ & -3 & $0.49 \pm 0.06^{b}$ & -19 & $1.4 \pm 0.03^{b c}$ & 19 & $0.73 \pm 0.02^{a}$ & 5 \\
\hline 4.2 & $1.1 \pm 0.15^{a}$ & -6 & $0.49 \pm 0.06^{b}$ & -20 & $1.4 \pm 0.02^{b c}$ & 18 & $0.72 \pm 0.01^{a}$ & 6 \\
\hline 4.9 & $1.0 \pm 0.14^{a}$ & -2 & $0.49 \pm 0.06^{b}$ & -19 & $1.4 \pm 0.02^{b c}$ & 22 & $0.69 \pm 0.01^{b}$ & 10 \\
\hline 11 (punctual) & $0.99 \pm 0.16^{a}$ & 1 & $0.48 \pm 0.05^{b}$ & -18 & $1.2 \pm 0.05^{c}$ & 31 & $0.67 \pm 0.02^{b}$ & 13 \\
\hline 11 (repeated) & $0.86 \pm 0.02^{a}$ & 14 & $0.43 \pm 0.02^{a b}$ & -5 & $0.78 \pm 0.01^{d}$ & 56 & $0.57 \pm 0.01^{d b}$ & 26 \\
\hline
\end{tabular}

bacterial strain-dependent. Indeed, highest functionality losses recorded for punctually-applied shear rates range from -20\% (functionality gain) for LGG spaCBA to more than $50 \%$ for LGG welE.

The wild type strain is the one which adhesive functionality is the less affected by shear stress. When punctually applied, shear stress appears not to impact bacterial functionality at all. Even when the highest shear rate is applied repeatedly, functionality losses remain inferior to $20 \%$, this loss itself not being statistically significant although this is probably due to the small number of measurements taken for this condition (4) compared to the others (30).

The adhesion of the pili-depleted strain LGG spaCBA was increased by shear stresses up to $20 \%$ for low shear rates. However, when the highest shear rate is repeatedly applied, the bacterial functionality gets back to the control level. This could be explained by partial removal of the EPS layer covering the surface of LGG spaCBA at low shear rates, which would expose other adhesive surface proteins. This is supported by the fact that the double mutant strain LGG D2 (pili- and EPS-depleted) was found to have an adhesive capacity superior to LGG spaCBA in control conditions, which could be due to the presence of other adhesive proteins on the cell surface (usually hidden under the EPS layer). The existence of such proteins has previously been brought to light ${ }^{28}$. Potential candidates that would mediate adhesion in the absence of pili include the Mucus Binding Factor MBF, the protein MbA, lipoteichoïc acids or peptidoglycans, all present on the surface of LGG cells underneath the EPS layer ${ }^{17,28}$. The EPS themselves have been previously found to play a role in adhesion ${ }^{28}$.

However, the strain LGG D2 also features functionality losses for high shear rates (reaching 10\% of functionality losses for 4.9 $\times 10^{5} \mathrm{~s}^{-1}$ ), leading to think that these other proteins may also get damaged by shear stress, whereas the functionality gain of LGG spaCBA is only reduced when the highest shear rate is repeatedly applied. A hypothesis could be that the EPS layer of LGG spaCBA was never completely removed when shear stress was only punctually applied, and that the remaining parts of this layer may surround and therefore "protect" the EPS-removal sites that reveal the underlying protein layer. Less forces are therefore exerted on these more "buried" sites which are more preserved and could later act as adhesive patches. However, when the highest shear rate is repeatedly applied, the EPS of LGG spaCBA would be more completely removed and therefore the underlying layer more damaged, leading to a decrease in functionality gain.

The strain LGG welE, initially the most adhesive strain, was also found to be the most stress-sensitive strain amongst the four strains tested. Losses seem to occur in increments, and do happen even for shear rates as low as $244 \mathrm{~s}^{-1}$. For shear rates from $3.0 \times 10^{5}$ to $4.9 \times 10^{5} \mathrm{~s}^{-1}$, losses approach $20 \%$, whereas for the highest shear rate, losses reach respectively $31 \%$ and $56 \%$ for punctually- vs. repeatedly-applied stress. The fact that LGG welE is a lot more sensitive to stress than LGG WT may be due to the fact that pili would be partially protected by the EPS layer featured by LGG WT, which could prevent their removal and limit the forces exerted at the pili basis. The full pili-exposure of LGG welE, presented in previous studies as a competitive advantage inducing higher adhesive capacities ${ }^{18,30,39}$, is found here to be a competitive disadvantage regarding the strain resistance to stress.

It can also be noticed that even when the highest shear rate is repeatedly applied, all strains still present significant adhesive differences from one another. This suggests that each strain features a basal functionality level below which it does not seem possible to get. However, basal functionality levels are not necessarily arranged in the same order than initial functionality levels (before shearing). Although LGG spaCBA is still the least adhesive strain and LGG D2 the second least adhesive strain after shearing, before shearing LGG welE was the most adhesive strain whereas after repeatedly-applied stress it becomes the second most adhesive, LGG WT becoming the first. This confirms the idea that LGG welE is the most stress-sensitive strain amongst the four strains tested.

Finally, functionality loss can be correlated with chain breakage for most strains (except the wild type), as the main shear stress impact on functionality occurs even at the lowest air pressures $\left(P=0.2\right.$ bars, $\dot{\gamma} \approx 3.0 \times 10^{5} s^{-1}$ ), in parallel to the drastic increase in proportion of 2-cell chains for the same shear rate. Although functionality losses globally increase with the shear rate, these increments are small compared to the first loss experienced at the lowest air pressure. Reasons for why most of the functionality losses occur at low shear rates will be explored in the modeling part.

Figure 5 sums up the main effects of shear stress observed experimentally on both bacterial physical state (chains and flocs) and bacterial functionality. 


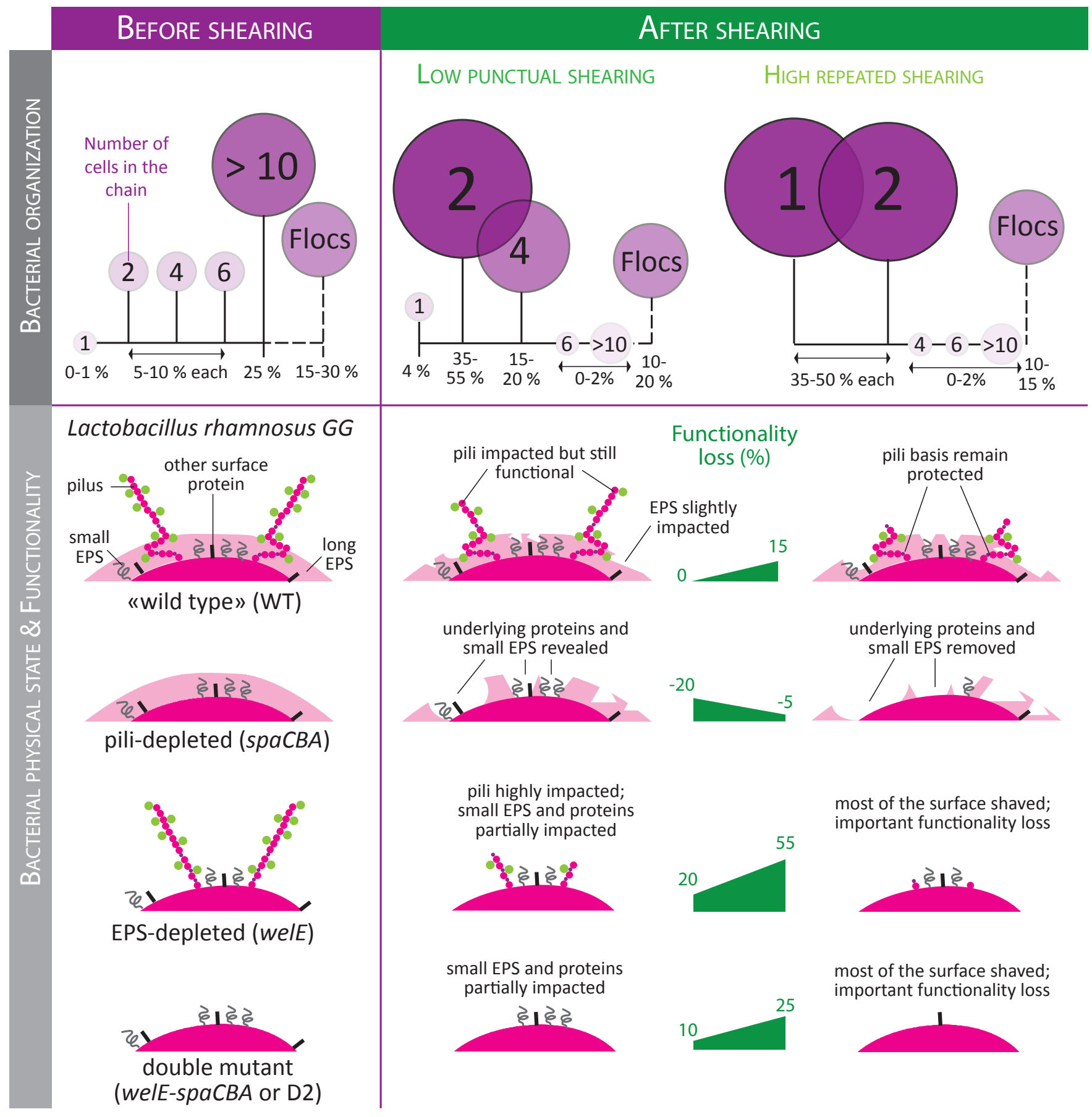

Fig. 5 Summary of the effects of shear flow on bacterial organization, bacterial physical state, and bacterial functionality for the strain Lactobacillus rhamnosus GG and three mutant strains driven from experimental observations; negative functionality percentages indicate a functionality gain. 


\section{Constitutive model}

\subsection{Bacterial chain breakage}

\subsubsection{Bacterial cell connections sensitive to shear stress.}

4.1.2 Breakage prediction depending on initial chain length and shear rate.

An analytic model to predict bacterial chain length distribution after shearing as a function of initial chain distribution and shear rate was built from the experimental data collected.

\subsection{Shear stress impact on bacterial surface}

\section{Conclusions}

\section{References}

1 F. J. Carr, D. Chill and N. Maida, 2002, 28, 281-370.

2 K. Khalid and others, 2011, 1, 1-13.

3 S. A. Hayek and S. A. Ibrahim, 2013, 04, 73-87.

4 E. J. Quinto, P. Jiménez, I. Caro, J. Tejero, J. Mateo and T. Girbés, 2014, 05, 1765-1775.

5 R. Ranadheera, S. Baines and M. Adams, 2010, 43, 1-7.

6 M. E. Sanders, T. R. Klaenhammer, A. C. Ouwehand, B. Pot, E. Johansen, J. T. Heimbach, M. L. Marco, J. Tennilä, R. P. Ross, C. Franz, N. Pagé, R. D. Pridmore, G. Leyer, S. Salminen, D. Charbonneau, E. Call and I. Lenoir-Wijnkoop, 2014, 1309, $1-18$.

7 F. Gomand, F. Borges, J. Burgain, J. Guerin, A.-M. RevolJunelles and C. Gaiani, 10, 285-310.

8 A. C. Ouwehand, E. M. Tuomola, S. Tölkkö and S. Salminen, 2001, 64, 119-126.

9 G. Deepika, R. A. Rastall and D. Charalampopoulos, 2011, 59, 8661-8666.

10 M. E. Sanders and M. L. Marco, 2010, 1, 65-85.

11 S. B. Doherty, L. Wang, R. P. Ross, C. Stanton, G. F. Fitzgerald and A. Brodkorb, 2010, 82, 301-310.

12 J. Guerin, J. Burgain, F. Gomand, J. Scher and C. Gaiani, 0, $1-13$.

13 D. Comfort and R. T. Clubb, 2004-05-01, 72, 2710-2722.

14 A. W. Maresso and O. Schneewind, 2008-03-01, 60, 128-141.

15 O. Schneewind and D. Missiakas, 2014-08, 1843, 1687-1697.

16 M. Kankainen, L. Paulin, S. Tynkkynen, I. v. Ossowski, J. Reunanen, P. Partanen, R. Satokari, S. Vesterlund, A. P. A. Hendrickx, S. Lebeer, S. C. J. D. Keersmaecker, J. Vanderleyden, T. Hämäläinen, S. Laukkanen, N. Salovuori, J. Ritari, E. Alatalo, R. Korpela, T. Mattila-Sandholm, A. Lassig, K. Hatakka, K. T. Kinnunen, H. Karjalainen, M. Saxelin, K. Laakso, A. Surakka, A. Palva, T. Salusjärvi, P. Auvinen and W. M. d. Vos, 2009, 106, year.

17 S. Lebeer, I. Claes, H. L. P. Tytgat, T. L. A. Verhoeven,
E. Marien, I. v. Ossowski, J. Reunanen, A. Palva, W. M. d. Vos, S. C. J. D. Keersmaecker and J. Vanderleyden, 78, 185-193.

18 J. Guerin, J. Bacharouche, J. Burgain, S. Lebeer, G. Francius, F. Borges, J. Scher and C. Gaiani, 58, 35-41.

19 K. A. Kline, S. Fälker, S. Dahlberg, S. Normark and B. Henriques-Normark, 2009-06-18, 5, 580-592.

20 K. A. Kline, K. W. Dodson, M. G. Caparon and S. J. Hultgren, 2010-05, 18, 224-232.

21 J. Reunanen, I. v. Ossowski, A. P. A. Hendrickx, A. Palva and W. M. d. Vos, 2012, 78, 2337-2344.

22 A. Persat, C. D. Nadell, M. K. Kim, F. Ingremeau, A. Siryaporn, K. Drescher, N. S. Wingreen, B. L. Bassler, Z. Gitai and H. A. Stone, 2015-05-21, 161, 988-997.

23 O. Björnham and O. Axner, 2009, 130, 235102.

24 W. M. Weaver, S. Dharmaraja, V. Milisavljevic and D. D. Carlo, 2011, 11, 883-889.

25 Pappelbaum Karin I., Gorzelanny Christian, Grässle Sandra, Suckau Jan, Laschke Matthias W., Bischoff Markus, Bauer Corinne, Schorpp-Kistner Marina, Weidenmaier Christopher, Schneppenheim Reinhard, Obser Tobias, Sinha Bhanu and Schneider Stefan W., 2013, 128, 50-59.

26 S. Lecuyer, R. Rusconi, Y. Shen, A. Forsyth, H. Vlamakis, R. Kolter and H. A. Stone, 2011, 100, 341-350.

27 F. Gomand, F. Borges, D. Salim, J. Burgain, J. Guerin and C. Gaiani, 84, 537-544.

28 J. Guerin, J. Burgain, G. Francius, S. El-Kirat-Chatel, A. Beaussart, J. Scher and C. Gaiani, 82, 296-303.

29 P. Tripathi, A. Beaussart, D. Alsteens, V. Dupres, I. Claes, I. von Ossowski, W. M. de Vos, A. Palva, S. Lebeer, J. Vanderleyden and Y. F. Dufrêne, 7, 3685-3697.

30 S. Lebeer, T. L. A. Verhoeven, G. Francius, G. Schoofs, I. Lambrichts, Y. Dufrêne, J. Vanderleyden and S. C. J. D. Keersmaecker, 75, 3554-3563.

31 P. Tripathi, V. Dupres, A. Beaussart, S. Lebeer, I. J. J. Claes, J. Vanderleyden and Y. F. Dufrêne, 28, 2211-2216.

32 A. Ghandi, I. B. Powell, T. Howes, X. D. Chen and B. Adhikari, 2012, 113, 194-200.

33 P. D. Hede, P. Bach and A. D. Jensen, 2008, 63, 3821-3842.

34 F. Wong, L. D. Renner, G. Özbaykal, J. Paulose, D. B. Weibel, S. van Teeffelen and A. Amir, 2017, 2, 17115.

35 W. Pönisch, C. A. Weber, G. Juckeland, N. Biais and V. Zaburdaev, 2017, 19, 015003.

36 H. L. Goldsmith and J. C. Marlow, 1979, 71, 383-407.

37 P. A. Aarts, S. A. van den Broek, G. W. Prins, G. D. Kuiken, J. J. Sixma and R. M. Heethaar, 1988, 8, 819-824.

38 D. Gidaspow and V. Chandra, 2014, 117, 107-113.

39 J. Burgain, J. Scher, S. Lebeer, J. Vanderleyden, C. CailliezGrimal, M. Corgneau, G. Francius and C. Gaiani, 41, 60-70. 